\title{
Preliminary Assessment of a Coupled Dynamic-Energy Budget and Agent-based Model (DEB-ABM) for Predicting Individual and Population-Level Dynamics: A Case Study on Anchovy, Engraulis japonicus
}

\author{
Baochao Liao $^{1,2}$, Xiujuan Shan ${ }^{2,3 *}$ and Yunlong Chen ${ }^{2,3}$ \\ ${ }^{1}$ Department of Mathematics and Statistics, Shandong University, Weihai, Shandong \\ 264209, China \\ ${ }^{2}$ Function Laboratory for Marine Fisheries Science and Food Production Processes, \\ Qingdao National Laboratory for Marine Science and Technology, Qingdao, \\ Shandong 266237, China \\ ${ }^{3}$ Yellow Sea Fisheries Research Institute, Chinese Academy of Fishery Sciences, \\ Qingdao, Shandong 266071, China
}

\section{A B S T RA C T}

Dynamic energy budget (DEB; also known as Kooijman-Metz DEB) theory is a well-tested framework for modelling energy acquisition, and for describing vital rates at which organisms acquire and use energy, such as for growth and reproduction. The coupling of a DEB with an agent-based model (generating a DEB- ABM) enables examination of the effects of environmental change at a population-level on a species to be examined. The present study applied a DEB-ABM to the Japanese anchovy Engraulis japonicus. The DEB-ABM accurately captured energy acquisition and allocation throughout the anchovy lifecycle (egg, yolk sac larva, exogenous feeding larva, juvenile, and adult) and predicted how individuallevel processes affect energy dynamics at higher levels of biological organization. We estimated primary model parameters (e.g., energy conductance, $\grave{v}$; allocation coefficient, $\kappa$; and volume-specific somatic maintenance, $\left.\left[\dot{p}_{\mathrm{M}}\right]\right)$, and for a 5-year simulation, calculated a mean population growth rate $\left(r_{\mathrm{p}}\right)$ of 3.4 year ${ }^{-1}$. When DEB theory is combined with an ABM, the combined model describes the dynamics of a population of individuals, where each individual follows an energy budget model. Predicted demographic rates (growth, survival, reproduction) fall within observed ranges, fit average recorded values, and captured known seasonal trends. The DEB-ABM correlated intrinsic and density-independent population growth rates, and may be useful for predicting the metabolic responses of individuals or populations to environmental change.

Article Information
Received 22 February 2020
Revised 04 April 2020
Accepted 23 April 2020
Available online 30 March 2021
Authors' Contribution
BL conceived and designed the study.
XS arranged the data. BL and YC
helped in data analysis. YC prepared
the Figures. BL analyzed the data and
wrote the article.
Key words
Dynamic energy budget, Agent-based
model, Fishery surveys, Engraulis
japonicus

\section{INTRODUCTION}

$\mathrm{D}$ ynamic energy budget (DEB; also known as the Kooijman-Metz DEB) theory links the physiological processes of individual organisms into a single framework (van der Meer, 2006; Kooijman, 2010). The theory describes the energy and matter fluxes within an individual, and between it and its environment (Kooijman, 2010; Marn, 2016; Agüera et al., 2017). Traditional DEB bioenergetic models are applied at the level of the individual, and can be used to deduce the energy input from individual-level growth and reproduction

\footnotetext{
* Corresponding author: shanxj@ysfri.ac.cn 0030-9923/2021/0003-1089 \$ 9.00/0

Copyright 2021 Zoological Society of Pakistan
}

(Kooijman, 2010; Jusup et al., 2011; Marn, 2016; Birnir et al., 2018). This theory systematically describes how an organism acquires and uses energy and other physiologically essential elements (Nisbet et al., 2012), and provides a framework within which the effects of environmental variables, such as food density, and temperature, influence physiological performance (Jusup et al., 2011; Marn, 2016).

An agent-based model (ABM) predicts how individual-level processes affect energy dynamics at higher levels of biological organization (Railsback and Grimm, 2011; Martin et al., 2013). ABMs have been widely used to predict the performance of a given population in response to fluctuations in regional environments (Sibly et al., 2013). When DEB theory is coupled with an ABM, the combined model, a DEB-ABM, describes the dynamics 
of a population of individuals, with each individual following an energy budget model (Railsback and Grimm, 2011; Sibly et al., 2013). This combined model can be used to predict how the energy dynamics at higher levels of biological organisation emerge from individual-level processes (Sibly et al., 2013). DEB models have been coupled with ABMs to study fish population dynamics in a large body of work (Martin et al., 2013; Sibly et al., 2013; Grossowicz et al., 2017; Desforges et al., 2017; Smallegange et al., 2017).

The pelagic Japanese anchovy (Engraulis japonicus; Temminck and Schlegel, 1846) is an important prey species and plankton feeder; it is also the most abundant fish in Chinese waters, including the Bohai $(\mathrm{BH})$, Yellow (YS), and East China (ECS) seas (Jin, 2004; Wang et al., 2003). However, increased fishing effort in Chinese waters in recent decades has led to dramatic changes in the population structure of the anchovy fishery. This small, rapidly reproducing fish has a life span of approximately 4 years (Iversen et al., 1993); it acquires a portion of its reproductive energy reserves during a productive period a few months before spawning season (Zhao et al., 2003; Zhao et al., 2008). Individuals grow rapidly during their first year, and mature after their first winter ( $\mathrm{Zhu}$ and Iversen, 1990; Chiu and Chen, 2001). Their life-cycle includes five stages: egg, yolk sac larva, exogenous feeding larva, juvenile, and adult (Wan and Bian, 2012; Wang et al., 2003).

In this present study, the DEB-ABM model analyzed the contributions of different energy sources and calculated the energy budget required to maintain growth and reproduction of a small and rapidly reproducing species E. japonicus in Chinese seas. Our aims are to: i) find a parameterized method and a validation of model output; (ii) present a novel model for investigating the dynamic population-level energy budget of anchovy; and iii) determine the most relevant quantitative variable to explain energy budgets relevant to growth and reproduction of anchovies across study areas.

\section{MATERIALS AND METHODS}

\section{Data collection}

The study area included the regions YS- $1\left(33^{\circ} 30^{\prime}\right.$ $\left.37^{\circ} 00^{\prime} \mathrm{N}, 129^{\circ} 00^{\prime}-124^{\circ} 00^{\prime} \mathrm{E}\right)$ and YS-2 (32 $00^{\circ}-39^{\circ} 00^{\prime}$ $\left.\mathrm{N}, 121^{\circ} 00^{\prime}-125^{\circ} 00^{\prime} \mathrm{E}\right)$. Data on spawning adults were collected every May (peak anchovy spawning season), from 2000 to 2004, as part of the pelagic acoustic surveys undertaken by the Chinese-Norwegian "BeiDou" project (Wan and Bian, 2012). Fishery surveys were conducted in three anchovy spawning grounds: the south of the Shandong Peninsula (in Laizhou Bay of the BS), the YS, and the coastal waters of the ECS (Zhao, 2006; Zhu et al., 2007; Wan and Bian, 2012; Wang et al., 2003). In the YS, adult anchovies spawn between May and September, with spawning peaking in May-June (Zhinan et al., 2002; Wang et al., 2003). Individual-level data on length, weight, and age are available for the period 2000-2004 (Kim et al., 2005; Zhao, 2006; Zhu et al., 2007; Wan and Bian, 2012; Wang et al., 2003). Satellite-derived sea surface water temperatures were obtained from the International Research Institute for Climate Prediction (IRI/LDEO) Climate Data Library (Wang et al., 2003; Shan et al., 2017).

\section{Individual-level}

The DEB model predicts individual energy allocation, acquisition, and use for growth and reproduction (Kooijman, 2010; Nisbet et al., 2012). Food intake was controlled by a scaled (dimensionless and Holling type-II) functional feeding response $(f)$ curve that ranged between 0 (i.e., no food intake) and 1 (i.e., maximum food intake); a fixed fraction of $\kappa$ was allocated to maintenance and growth, and the remaining energy $(1-\kappa)$ was utilized for development and reproduction (Table I). The food uptake was proportional to the surface area of the larva and to food density. The ingestion rate was equal to $\dot{p}_{X}=f(X) *\left\{\dot{p}_{X}\right\}^{*} \mathrm{~V}^{2 / 3}$, where $f(X)=X /(X+\mathrm{K})$. The four state variables (fluxes, units: $\mathrm{J}$ day $\left.^{-1}\right)$, including the Arrhenius temperature $\left(T_{\mathrm{A}}\right)$; the volume-specific somatic maintenance $\left(\left[\dot{p}_{\mathrm{M}}\right]\right)$; energy conductance $(\hat{v})$; allocation coefficient $(\kappa)$; fraction of energy allocated to fixed growth $\left(\kappa_{\mathrm{G}}\right)$; and maturity maintenance rate coefficient $\left(\kappa_{\mathrm{J}}\right)$. DEB dictated that energy is assimilated $\left(\dot{p}_{\mathrm{A}}\right)$ from food and transferred into reserve $(E)$. The fixed fractions ( $\kappa$ and $1-\kappa$ ) of the catabolized energy $\left(\dot{p}_{\mathrm{C}}\right)$ are allocated to either soma $\left(E_{\mathrm{v}}\right.$, units: J) or maturation/reproduction $\left(E_{\mathrm{R}}\right)$. Increases in anchovy size $(V)$ regulated transitions between developmental stages. All energy allocated to the reproductive buffer before puberty $\left(V<V_{\mathrm{P}}\right)$ was lost to maturation $\left(E_{\mathrm{R}}=0\right)$. DEB model was parameterized based on the biometric data of juveniles and adult $E$. japonicus (SL range: $5.8-17.2 \mathrm{~cm}$ ) collected between 2001 and 2004 (Wan et al., 2004; Zhao, 2006). Anchovy water mass $W_{\text {ww }}$ was predicted by the following equation: $W_{\mathrm{ww}}=\exp (-3.19+0.38 * l+0.59 * \log (\mathrm{e})-0.035$ $* l * \log (\mathrm{e}))$; this length-weight relationship is typically expressed as $W=a \times L^{b}$. Larval growth data were consisted of individual specimens (Total length: $1.8-5.4 \mathrm{~cm}$; $W_{\mathrm{ww}}$ : $0.018-1.32 \mathrm{~g}$ ). Larval growth and proximate composition data for anchovies were used to estimate the values of the state variables as follows: $E_{\mathrm{R} 0}=0 \mathrm{~J} ; E_{\mathrm{GAM} 0}=0 \mathrm{~J} ; E_{0}=0.11 \mathrm{~J}$; $E_{\mathrm{V} 0}=0.025 \mathrm{~J}$; and $V_{0}=0.00013 \mathrm{~cm}^{3}$. We set the length- and weight-at-first-feeding (day 4) values to $0.292 \mathrm{~cm}$ and $0.031 \mathrm{~g}$, respectively (Wan et al., 2002; Wan and Bian, 
2012). The relationship between water temperature $T$ and egg development time $D$ for the anchovy was expressed as
$D=1788.42(T-273)^{-2.29}$. The DEB model parameter values are summarized in Table II.

Table I. Equations of the dynamic energy budget model fluxes and model output variables. All parameter values listed in Table II, and a conceptual diagram is shown in Kooijman 2010.

\begin{tabular}{|c|c|c|}
\hline Formula & Description & Type (/units) \\
\hline$\dot{p}_{A}=\left\{\dot{p}_{A M}\right\} \cdot f \cdot V^{2 / 3}$ with $\left\{\dot{p}_{A M}\right\}=\left\{\dot{p}_{X M}\right\} a e$ & Assimilation & Fluxes $\left(\mathrm{J} \mathrm{d}^{-1}\right)$ \\
\hline$\dot{p}_{C}=\frac{[E]}{\left[E_{G}\right]+\kappa[E]}\left(\frac{\left[E_{G}\right]\left\{\dot{p}_{A M}\right\} V^{2 / 3}}{\left[E_{m}\right]}+\left[\dot{p}_{M}\right] V\right)$ & Catabolic utilization & Fluxes $\left(\mathrm{J} \mathrm{d}^{-1}\right)$ \\
\hline$\dot{p}_{G}=\kappa \dot{p}_{C}-\dot{p}_{M}$ & Growth & Fluxes $\left(\mathrm{J} \mathrm{d}^{-1}\right)$ \\
\hline$\dot{p}_{M}=\left[\dot{p}_{M}\right] V$ & Somatic maintenance & Fluxes $\left(\mathrm{J} \mathrm{d}^{-1}\right)$ \\
\hline$\dot{p}_{R}=(1-\kappa) \dot{p}_{C}-\dot{p}_{J}$ & Reproduction & Fluxes $\left(\mathrm{J} \mathrm{d}^{-1}\right)$ \\
\hline$\dot{p}_{J}=\min \left(\frac{1-\kappa}{\kappa} \cdot\left[\dot{p}_{M}\right] V, \frac{1-\kappa}{\kappa} \cdot\left[\dot{p}_{M}\right] V_{p}\right)$ & Maturity maintenance & Fluxes $\left(\mathrm{J} \mathrm{d}^{-1}\right)$ \\
\hline$\dot{p}_{G}=\kappa \dot{p}_{C}-\dot{p}_{M}$ & $\begin{array}{l}\text { Gamete allocation (syn- } \\
\text { thesis) }\end{array}$ & Fluxes $\left(\mathrm{J} \mathrm{d}^{-1}\right)$ \\
\hline $\begin{array}{l}\dot{p}_{R 2}=E_{R}\left(\frac{\left\{\dot{p}_{A M}\right\}}{\left[E_{m}\right] V^{1 / 3}}+\frac{\left[\dot{p}_{M}\right]}{\left[E_{G}\right]}\right)(1-\kappa) \frac{E}{\left[E_{G}\right] V+\kappa E} \\
\operatorname{ifSST}(t)>T R, \text { else }=0\end{array}$ & $\begin{array}{l}\text { Gamete (energy mobi- } \\
\text { lization) }\end{array}$ & Fluxes $\left(\mathrm{J} \mathrm{d}^{-1}\right)$ \\
\hline$\dot{p}_{M 2}=\min \left(\dot{p}_{M}-\kappa \dot{p}_{C}, \dot{p}_{R 2}\right)$ & $\begin{array}{l}\text { Emergency somatic } \\
\text { maintenance }\end{array}$ & Fluxes $\left(\mathrm{J} \mathrm{d}^{-1}\right)$ \\
\hline$\left.\dot{p}_{M 3}=\max \left(\dot{p}_{M}-\left(\kappa \dot{p}_{C}+\dot{p}_{M 2}\right)\right) /\left[E_{G}\right], 0\right)$ & $\begin{array}{l}\text { Atresia (gonad resorp- } \\
\text { tion) }\end{array}$ & Fluxes $\left(\mathrm{J} \mathrm{d}^{-1}\right)$ \\
\hline$L=V^{1 / 3} / \delta_{\text {larvae }}$ elseV $V^{1 / 3} / \delta_{\text {adults }}$ if $V>V_{m o r p h}$ & Total length $(L)$ & Model output (cm) \\
\hline$W_{c h v}=E_{V} / \mu_{V}+\left(\left(E_{R}+E\right) / \mu_{E}\right)\left(E_{G A M} / \mu_{G}\right)$ & Total dry weight $\left(W_{\mathrm{dw}}\right)$ & Model output (g) \\
\hline$W_{w w}=W_{c w} \cdot \gamma$ & Total wet weight $\left(W_{\mathrm{ww}}\right)$ & Model output (g) \\
\hline$W_{G O N}=\left(0.015 E_{V} / \mu_{V}+E_{G A M} / \mu_{G}\right) \cdot \gamma$ & Gonad weight $\left(W_{\mathrm{GON}}\right)$ & Model output (g) \\
\hline$E d=\frac{\left(E_{V}+E+E_{R}+E_{G A M}\right)}{W_{d w}\left(o r W_{w w}\right)}$ & Energy density $\left(E_{\mathrm{d}}\right)$ & Model output ( $\left.\mathrm{J} \mathrm{g}^{-1}\right)$ \\
\hline$K_{f u l}=100 W_{w w} / L^{3}$ & Condition index $\left(K_{\mathrm{ful}}\right)$ & Model output $\left(\mathrm{g} \mathrm{cm}^{3}\right)$ \\
\hline$G S I=W_{G O N} \times 100 / W_{w v}$ & $\begin{array}{l}\text { Gonad somatic index } \\
\text { (GSI) }\end{array}$ & Model output (-) \\
\hline
\end{tabular}


Table II. List of parameter values of the dynamic energy budget model for anchovy, Engraulis japonicus.

\begin{tabular}{|c|c|c|c|}
\hline Parameters & Symbol & Definition & Unit \\
\hline Max. assimilation rate & $\dot{p}_{\mathrm{AM}}$ & Feeding parameter & $\mathrm{J} \mathrm{cm}^{-2} \mathrm{~d}^{-1}$ \\
\hline Assimilation efficiency & $a e$ & Feeding parameter & Dimensionless \\
\hline Volume specific cost for structure & $E_{G}$ & Energetic parameter & $\mathrm{J} \mathrm{cm}^{-3}$ \\
\hline Volume specific maintenance cost & $\dot{p}_{\mathrm{M}}$ & Energetic parameter & $\mathrm{J} \mathrm{cm}^{-2} \mathrm{~d}^{-1}$ \\
\hline Fraction of energy allocated to growth & $\kappa$ & Energetic parameter & Dimensionless \\
\hline Max. storage rate & $E_{m}$ & Energetic parameter & $\mathrm{J} \mathrm{cm}^{-3}$ \\
\hline Maturity maintenance rate coefficient & $\dot{k}_{j}$ & Maturity coefficient & $d^{-1}$ \\
\hline Maturity threshold at birth & $H_{B}$ & Maturity coefficient & $\mathrm{J}$ \\
\hline Maturity threshold at puberty & $H_{P}$ & Maturity coefficient & $\mathrm{J}$ \\
\hline Half saturation coefficient for food & $K_{F}$ & Saturation coefficient & $\mathrm{g} \mathrm{cm}^{-3}$ \\
\hline Fraction of energy fixed into eggs & $K_{R}$ & Saturation coefficient & Dimensionless \\
\hline Energy conductance & $\dot{v}$ & Energy conductance & $\mathrm{cm} \mathrm{d}^{-1}$ \\
\hline \multicolumn{4}{|l|}{ Auxiliary and compound parameters } \\
\hline Size at first feeding & $l_{b}$ & 4.1 & $\mathrm{~mm}$ \\
\hline Size at metamorphosis & $l_{j}$ & 4.1 & $\mathrm{~cm}$ \\
\hline Energy in reserve at first feeding & $E_{b}$ & 0.11 & $\mathrm{~J}$ \\
\hline Energy of eggs & $E_{0}$ & 0.66 & $\mathrm{~J} \mathrm{eggs}^{-1}$ \\
\hline Relative batch fecundity & $R_{b F}$ & 478.9 & eggs $g^{-1}$ \\
\hline Spawning frequency & $\dot{S}_{f}$ & 0.33 & $d^{-1}$ \\
\hline Shape coefficient (early larva) & $\delta_{b}$ & Estimate & Dimensionless \\
\hline Acceleration factor (larvae) & $f_{a c c}$ & Estimate & Dimensionless \\
\hline Density of structure & $d_{v}$ & Estimate & $\mathrm{g} \mathrm{cm}^{-3}$ \\
\hline Energy density of structure & $\rho_{v}$ & Estimate & $\mathrm{J} \mathrm{g}^{-1}$ \\
\hline Energy density of reserve & $\rho_{E}$ & Estimate & $\mathrm{J} \mathrm{g}^{-1}$ \\
\hline Energy density of reproduction reserve & $\rho_{R}$ & Estimate & $\mathrm{J} \mathrm{g}^{-1}$ \\
\hline Energy density of gametes & $\rho_{C}$ & 23880 & $\mathrm{~J} \mathrm{~g}^{-1}$ \\
\hline
\end{tabular}

\section{Population-level}

Population-level dynamics describe those of a population of individuals, where each individual follows an energy budget model (Martin et al., 2013; Sibly et al., 2013). The $i$-states in our model follow DEB characteristics in their size $(V)$, reproductive output $\left(E_{\mathrm{R}}, E_{\mathrm{GAM}}\right.$, and $\left.E_{\text {batch }}\right)$, and energy reserves $(E)$ (Pecquerie et al., 2009Sibly et al., 2013; Grossowicz et al., 2017), as follows:

$$
\begin{gathered}
\frac{d}{d t} E=\dot{p}_{A}-\dot{p}_{C}, \text { Reserve, E } \\
\frac{d}{d t} V=\dot{p}_{A} /\left[E_{G}\right], \text { Structure, } \quad V\left(\mathrm{~cm}^{3}\right) \\
\frac{d}{d t} E_{R}=\dot{p}_{R}-\dot{p}_{R 2} \quad \text { if } \quad V>V_{P}, \quad \text { else }=0 ; \text { with } E_{V}=\rho v d v V \\
\frac{d}{d t} E_{G A M}=\dot{p}_{C A M}-\dot{p}_{M 3}-E_{\text {batch }}^{*}, \text { Gametes, } E_{G A M} \\
\frac{d N_{i}}{d t}=-h_{i} \cdot N_{i}-m_{i} N_{i}, \quad\left(i \mathrm{nd} \mathrm{d}^{-1}\right) \\
S=\sum_{i} N_{i} \cdot W T_{i} \\
P=\sum_{i} h_{i} N_{i} \cdot W T_{i} \\
N=\sum_{i} N_{i}
\end{gathered}
$$

Where the variables $V_{\mathrm{i}}, E_{\mathrm{i}}, R_{\mathrm{i}}, L_{\mathrm{i}}$, and $W T_{\mathrm{i}}$ were associated with cohort $i$ and simulated with DEB equations; $h_{\mathrm{i}}$ represented the harvest rate coefficient; $m_{\mathrm{i}}$ was the natural mortality rate coefficient; $N_{\mathrm{i}}$ was the number of individuals in cohort $i$; $P$ was the cumulative harvest of cohorts; $N$ was the total number of individuals; and $S$ was the weight of all cohorts after summation to estimate the standing stock at each time step. The total recruitment $(R)$ was calculated as a function of spawning stock biomass (SSB) (Zhao et al., 2003). The characterized state variables of the individual were included reserves $(E)$, structure $(V$ and $\left.E_{\mathrm{v}}\right)$, reproduction $\left(E_{\mathrm{R}}\right)$, and gametes $\left(E_{\mathrm{GAM}}\right.$; Table I) (Regner, 1996; Boussouar et al., 2001). The sensitivities of the intrinsic model-specific parameters (deterministic, nondeterministic, positive, and negatively correlated) were investigated using a traditional one-parameter-ata-time analysis (OPAT), in which each model parameter was varied separately with $\pm 10 \%$ white noise (CV). We calculated a relative estimate error (REE) to compare results among CVs (Chen et al., 2010). The REE was 
evaluated by calculating a simple sensitivity index (SSI) as follows:

$$
\begin{gathered}
S S I_{1}=\sum_{i=1}^{k}\left(\left|W_{t}^{0}-W_{t}^{1}\right| / k W_{t}^{0}\right) * 100 \% \\
S S I_{2}=\frac{1}{k} \sum_{i=1}^{k}\left(\left|L_{t}^{0}-L_{t}^{1}\right| / L_{t}^{0}\right) * 100 \%
\end{gathered}
$$

Where $W_{\mathrm{t}}^{0}$ is the total estimated wet body weight in simulation (predicted with the new parameter value at time $t) ; W_{t}^{1}$ is the total actual wet body weight in simulation (predicted with the standard simulation at time $t) ; k$ is the number of simulated days; $L_{\mathrm{t}}^{0}$ is the total body length (predicted with the new parameter value at time $t$ ); and $L_{\mathrm{t}}^{1}$ is the total body length (predicted with the standard simulation at time $t$ ). The effects of external factors, including sea surface temperature (SST), natural mortality $\left(N_{0}\right)$, and food availability $(X)$, on the growth rate of individual anchovies (or anchovy populations) was evaluated using a number of scenario-based simulations.

\section{RESULTS}

\section{Individual traits}

The Arrhenius temperature $\left(T_{\mathrm{A}}\right)$ is an expression of the effects of temperature on biological reaction rates. Here, we obtained a mean $T_{\mathrm{A}}$ value of $9800 \pm 835 \mathrm{~K}$, which was determined by plotting $\ln (1 / D)$ against $1 / T$, where $D$ and $T$ are egg development time and temperature, respectively. We estimated two different Arrhenius relationships for the moving average (MA) of ingestion rate and respiration rate (Fig. 1). The average length- and weight-at-age of an individual anchovy collected in May predicted by our simulation were consistent with the actual length- and weight-at-age recorded during the same period by our surveys (2000-2004). We calculated energy density as the ratio of the total energy reserves to the total anchovy wet weight. By simulating differences in hatching dates in a seasonal environment, over several years, our model produced variability in anchovy body length and weight (Fig. 2). To convert state variables into units of weight $\left(\mathrm{g} W_{\mathrm{dw}}\right)$, we used separate conversion factors for structures $\left(E_{\mathrm{V}} ; \mu_{\mathrm{V}}=19.9 \mathrm{KJ} \mathrm{g}^{-1}\right)$, reserves $\left(E\right.$ and $E_{\mathrm{R}} ; \mu_{\mathrm{E}}=35.2 \mathrm{KJ}$ $\left.\mathrm{g}^{-1}\right)$, and gametes $\left(E_{\mathrm{GAM}} ; \mu_{\mathrm{G}}=33.2 \mathrm{KJ} \mathrm{g}^{-1}\right)$. As anchovies have different shapes as juveniles and adults, separate shape coefficients were estimated by fitting the weightlength relationship as $W_{\text {ww }}^{1 / 3} / \mathrm{L}$. The coefficients $\delta_{\text {Adult }}$ and $\delta_{\text {larvae }}$ were 0.169 and 0.154 , respectively. The threshold structural volumes at first feeding $\left(V_{\mathrm{ab}}\right)$, at metamorphosis $\left(V_{\text {morph }}\right)$, and at puberty $\left(V_{\mathrm{p}}\right)$ were estimated to be 0.000164 , 0.53 , and $5.43 \mathrm{~cm}^{3}$, respectively. The simulation was designed to validate the predictions of our model under conditions of prolonged starvation. The shape coefficient $\delta_{\mathrm{m}}$ was calculated as 0.172 , and the scaled reserve to mass converter $\left\{\dot{p}_{\mathrm{AM}}\right\} / \rho_{\mathrm{E}}$ was calculated as $\left\{\dot{p}_{\mathrm{AM}}\right\} / \rho_{\mathrm{E}}=0.00275$ $\mathrm{g} \mathrm{cm}^{-2}$ day $^{-1}$. The life-stage specific variables for the anchovy DEB-ABM are shown in Table III.

Table III. Life stage-specific variables for the anchovy dynamic energy budget-agent-based model, including

\begin{tabular}{|c|c|c|c|c|c|c|}
\hline & \multicolumn{5}{|c|}{ Food $\left(\mathrm{mg} \mathrm{m}^{-3}\right)$} & \multirow[t]{2}{*}{ f } \\
\hline & $\mathbf{X}_{\text {mean }}$ & $\mathbf{a}$ & $\omega$ & $\mathbf{K}$ & Prey & \\
\hline Yolk sac larvae & 0 & 0 & - & 0 & - & 0 \\
\hline Early larvae & 0.41 & 0.246 & 365 & 0.092 & $<0.2 \mathrm{~mm}$ & $0.65-0.85$ \\
\hline Late larvae & 0.41 & 0.247 & 355 & 0.092 & $<0.2 \mathrm{~mm}$ & $0.65-0.85$ \\
\hline Juveniles & 42 & 17 & 345 & 8.6 & $0.2-0.5 \mathrm{~mm}$ & $0.6-0.8$ \\
\hline \multirow[t]{3}{*}{ Adults } & 126 & 92 & 330 & 34 & $>0.5 \mathrm{~mm}$ & $0.45-0.9$ \\
\hline & $\mathbf{L}_{\max }(\mathrm{cm})$ & $A_{\max }(d)^{a}$ & $M\left(d^{-1}\right)$ & \multicolumn{3}{|c|}{ Temperature $\left({ }^{\circ} \mathrm{C}\right)$} \\
\hline & & & & $\mathbf{T}_{\text {mean }}$ & $\mathbf{a}$ & $\omega$ \\
\hline Yolk sac larvae & 0.31 & 4 & 0.621 & 18.5 & 4 & 238 \\
\hline Early larvae & 3.75 & 40 & 0.285 & 18 & 4 & 236 \\
\hline Late larvae & 5 & 80 & 0.053 & 17.5 & 4 & 232 \\
\hline Juveniles & 10.3 & 280 & 0.004 & 17 & 3 & 224 \\
\hline Adults & 14.5 & 1460 & 0.003 & 16 & 2 & 210 \\
\hline
\end{tabular}
mortality rates $(M)$, temperature $(T)$, scaled functional response $(f)$, and size thresholds $\left(L_{\max }\right)$.

Sinusoidal functions were applied using the equation $T(\mathrm{t})=T \quad+a \sin (2 \pi(\mathrm{t}+\omega) / 365), X(\mathrm{t})=X+a \sin (2 \pi(\mathrm{t}+\omega) / 365)$, where $X$ or $T$ is the mean value, $a$ is the amplitude, and $\omega$ is the phase shift of the sinusoid curve. For larvae, prey consists of phytoplankton sized $<0.2 \mathrm{~mm}$, juveniles feed on small zooplankton sized $0.2-0.5 \mathrm{~mm}$, and adults feed on large mesoplankton consisting of zooplankton sized $>0.5 \mathrm{~mm}$. $\mathrm{A}_{\max }$ is the given maximum age for five stages; $M=1$ at the end of age-4 (1825 days). 


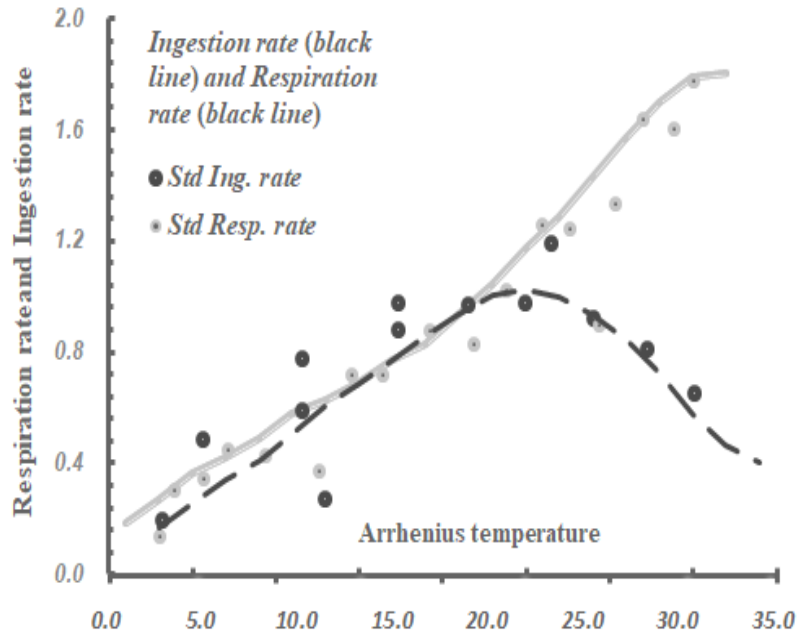

Fig. 1. Arrhenius relationships used to estimate ingestion rate (black line) and respiration rate (grey line); corrections given for temperatures from $3-32{ }^{\circ} \mathrm{C}$.
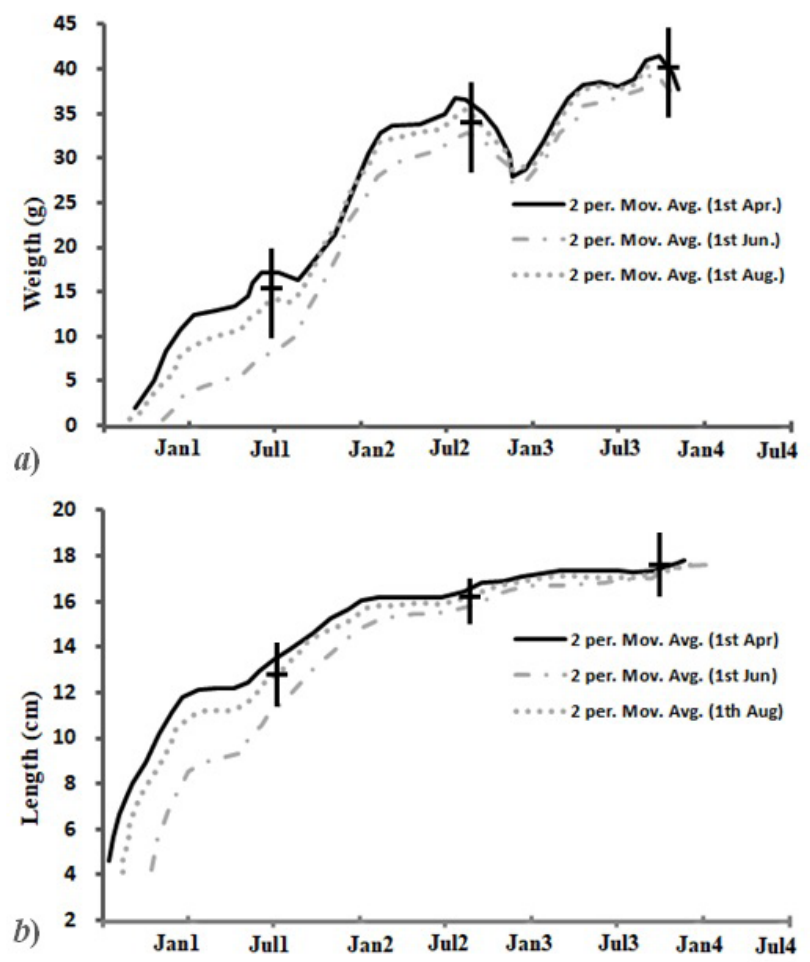

Fig. 2. Anchovy growth in weight (top panel) and -length (bottom panel) measured by simulations in hatching dates (May to September) from 2000-2004.

\section{Population traits}

In a 5-year simulation, we yielded a mean population (log-transformed biomass) growth rate $\left(r_{\mathrm{p}}\right)$ estimate of 3.4 year $^{-1}$. On the basis of a comparison of individual and population-level processes, the present study found that the sensitivities of age-specific annual fecundity and population rates to short-term environmental scenarios were similar. The simulation was designed to validate the predictions of the ABM (details of the anchovy ABM variables are shown in Table IV. By simulating multiple cohorts in an ABM, inter-individual variability in growth trajectories and reproductive potential became apparent. Age class 1 anchovies accounted for $30 \%-60 \%$ of the spawning stock; age class 2 accounted for $20 \%-50 \%$, age class 3 accounted for $10 \%-30 \%$, and age class 4 accounted for less than $10 \%$. Our model produced a pattern of biphasic growth when we varied food availability during the first stage of the anchovy life cycle. Longterm simulations were performed under different annual environmental conditions and hatching dates for length-atage and weight-at-age.

\section{DISCUSSION}

The DEB model describes vital rates at which organisms acquire and use energy for various activities, but it does not model energy allocation or growth at the population level (Sibly et al., 2013; Grossowicz et al., 2017). A combined DEB-ABM can, however, describe the dynamics of a population of individuals, where each individual follows an energy budget model (van der Meer, 2006; Kooijman, 2010). Therefore, an understanding of individual-level strategies is critical to determining the relationship between growth and time at a population level (Serpa et al., 2013; Gelman et al., 2014). The coupling of a DEB and ABM represents a promising method for prediction of population-level dynamics of species using individual data (Sibly et al., 2013).

We used simulations to predict the effects of SST and individual fish length on use of reproductive reserves for growth (Pethybridge et al., 2013; Sibly et al., 2013). During the spawning season, anchovy in age classes 2 and 3 lost an average of $25 \%$ of their weight, but those in age class 1 , which remained in a phase of rapid growth, did not. Length growth rates were highest for larvae $(0.55-$ $\left.0.84 \mathrm{~mm} \mathrm{~d}^{-1}\right)$, followed by juveniles $\left(0.10-0.55 \mathrm{~mm} \mathrm{~d}^{-1}\right)$. In age class 1 anchovies, most length and weight increases occurred between early spring and autumn, and length size increases decreased during the second year, between spring and summer. Overwinter decreases in $E_{D}$ were more significant for older fish than they were for younger fish, due to the increased cost of maintenance for larger fish. Parameterization for the anchovy model was conducted at the individual level to enable prediction of populationlevel effects or a wide range of environmental conditions (Pethybridge et al., 2013). 
Table IV. List of parameters for the agent-based model for anchovy (Engraulis japonicus).

\begin{tabular}{|c|c|c|c|}
\hline Symbol & Value & Unity & Variable \\
\hline$\overline{k_{\mathrm{C}}}$ & $1.57 \times 10^{-6}$ & Dimensionless & The intercept of the maximum consumption rate function \\
\hline$\tau \mathrm{c}$ & -0.256 & Dimensionless & The slope of the maximum consumption rate function \\
\hline \multicolumn{2}{|c|}{$\left(T_{1 C}, T_{2 C}, T_{3 C}, T_{4 C}\right)=(12,15,20,30)$} & ${ }^{\circ} \mathrm{C}_{1 \times 4}$ & Temperature value for $x_{1 C}, x_{2 C}, x_{3 C}$, and $x_{4 C}$ \\
\hline \multicolumn{2}{|c|}{$\left(k_{S 0}, k_{S 1}, k_{S 2}, k_{S 3}, k_{S 4}\right)=(0.125,0.175,0.175,0.175,0.175)$} & Dimensionless & $\begin{array}{l}\text { Coefficient for specific dynamic actionfor the age- } 0 \text {, age- } 1 \text {, } \\
\text { age- } 2 \text {, age- } 3 \text {, and age- } 4 \text {, i.e., }\left(k_{S 0}, k_{S 1}, k_{S 2}, k_{S 3}, k_{S 4}\right)\end{array}$ \\
\hline \multicolumn{2}{|c|}{$\begin{array}{l}\left(k_{E g 0}, k_{E g 1}, k_{E g 2}, k_{E G 3}, k_{E g 4}\right)=(0.125,0.160,0.160,0.160 \\
0.160)\end{array}$} & Dimensionless & $\begin{array}{l}\text { Proportion of consumed food egested for the age-0, age-1, } \\
\text { age-2, age-3, and age-4, i.e., }\left(k_{E g 0}, k_{E g 1}, k_{E g 2}, k_{E G 3}, k_{E g 4}\right)\end{array}$ \\
\hline \multicolumn{2}{|c|}{$\begin{array}{l}\left(x_{1 f}, x_{2 f}, x_{3 f}, x_{4 f}\right)_{4 \times 12}=(7,7,7,7,7,9,12,12,12,12,7,7 ; 11,11 \\
11,12,13,14,20,20,20,20,11,11 ; 13,13,13,14,16,17,26,2 \\
6,26,26,13,13 ; 15,15,15,16,18,21,30,30,30,30,15,15)\end{array}$} & ${ }^{\circ} \mathrm{C}_{4 \times 12}$ & $\begin{array}{l}\text { Temperature value (i.e., } x_{1 \mathrm{f}}, x_{2 \mathrm{f}}, x_{3 \mathrm{f}} \text {, and } x_{4 \mathrm{f}} \text { ) for the fitness } \\
\text { function corresponding to four temperatures, } T_{1 \mathrm{C}}, T_{2 \mathrm{C}}, T_{3 \mathrm{C}} \text {, } \\
\text { and } T_{4 \mathrm{C}} \text {, in } 12 \text { months, respectively }\end{array}$ \\
\hline \multicolumn{2}{|c|}{$\left(x_{1 C}, x_{2 C}, x_{3 C}, x_{4 C}\right)=(0.1,0.9,0.9,0.1)$} & Dimensionless & $\begin{array}{l}\text { Proportion of the maximum consumption rate }\left(C_{\max }\right) \text { at } x_{I C} \text {, } \\
x_{2 C}, x_{3 C} \text { and } x_{4 C}\end{array}$ \\
\hline$a_{s}$ & 151.1 & Dimensionless & The non-dimensional parameters in $R-S S B$ model \\
\hline$b_{s}$ & 0.299 & Dimensionless & The non-dimensional parameters in $R$ - SSB model \\
\hline
\end{tabular}

The $g(P)$ is a function expressed by $g(P)=\left(\Sigma P_{\mathrm{i}} \mathrm{v}_{\mathrm{i}} / K\right) /\left(1+\left(\Sigma P_{\mathrm{i}} / K\right)\right) ; i$ denotes the prey type $I=1,2,3 ; K$ is the half-saturation constant; $h(T)=g_{\mathrm{Tc} 1} \times g_{\mathrm{Tc} 2}$, $g_{\text {Tcl }}\left(x_{I C} * \mathrm{t}^{*}\right) /\left(1+x_{I C}\left(\mathrm{t}^{*}-1\right)\right)$; and $\left.g_{\mathrm{TCl}}=x_{4 C} * \mathrm{t}^{*}\right) /\left(1+x_{4 C}\left(\mathrm{t}^{*}-1\right)\right)$, where $x_{I C}, x_{2 C}, x_{3 C}$, and $x_{4 C}$ are the values of the Cmax function corresponding to four temperatures, $T_{I C}, T_{2 C}, T_{3 C}$, and $T_{4 C}$, respectively; $x_{10}, x_{20}, x_{30}$ and $x_{4 f}$ are the values of the fitness function corresponding to four temperatures, respectively; $\mathrm{t}^{*}=\exp \left\{\left[1 /\left(T_{2 C}-T_{I C}\right)\right]^{*}\left(T-T_{I C}\right)\right\} *\left[x_{2 C}\left(1-x_{I C}\right)\right] /\left[x_{I C}\left(1-x_{I C}\right)\right] ;$ and $\mathrm{t}^{*}=\exp \left\{\left[1 /\left(T_{4 C}-T_{3 C}\right)\right]^{*}\left(T-T_{3 C}\right)\right\}^{*}\left[x_{4 C}\left(1-x_{3 C}\right)\right] /\left[x_{4 C}\left(1-x_{3 C}\right)\right]$. Special dynamic action $(S)$ represents the energy allocated to the food digestive process: $S=k_{\mathrm{S}}\left(C-E_{\mathrm{g}}\right)$; and egestion $\left(E_{\mathrm{G}}\right)$ is a constant proportion of consumption; $E_{\mathrm{g}}=k_{\mathrm{Fg}} C$, where $k_{\mathrm{S}}$ is the proportion of assimilated energy lost to special dynamic action, and $k_{\mathrm{Eg}}$ is the scaling factors for egestion (Jin, 2004; Wang et al., 2003 ).

For the population-level ABM, relatively simple responses emerged from complex individual processes (Sibly et al., 2013). Population-level biomass and daily production varied with season, coinciding with numerical abundance. The length size of an individual often affects its survival, chance of reproduction, growth, and number and size of its offspring (Zuidema et al., 2010). In a 5-year simulation under standard environmental conditions, our model estimated a mean anchovy population (logtransformed biomass) growth rate $\left(r_{\mathrm{p}}\right)$ of $3.4 \mathrm{year}^{-1}$.

Many species have complex life cycles, with individuals at different stages classified by different attributes- e.g., plant populations have long-living seed banks, and an additional discrete-state variable is thus required to keep track of seed numbers (Ellner and Rees, 2006; Zuidema et al., 2010). After simulating multiple cohorts, inter-individual variations in reproductive potential due to inter-annual variability in environmental conditions became apparent. Intra-specific variation in population size was high during the first year and thereafter decreased with age. Using the DEB-ABM, we can begin to observe the action of population size and structure at the level of the individual. Similar observations, including population-level empirical generaliations, may be obtained once energy budget models are more routinely used in ABMs.

The DEB-ABM model explained many anchovy life history parameters well, including age-at-maturity, spawning interval, batch fecundity, seasonal fecundity, and condition dynamics. It increases our understanding of Yellow Sea anchovy reproductive strategies. Predicted feeding rates as a proportion of body weight are consistent with estimates based on stomach content $(2.5 \%-4 \%)$ reported by Sun et al. (2006). Predicted inter-spawning intervals at peak spawning season are within ranges typically given for anchovies (3-5 days). Individual growth of anchovy results from the integration of a series of processes, such as growth, reproduction, maturation, and activity (Celisse, 2008). Formultiple-batch spawners, the level of energy reserves available for reproduction determines the number of egg batches an individual will spawn (Jager and Klok, 2010).

\section{CONCLUSION}

This modelling approach, "the coupling of an ABM with DEB theory", captured the acquisition/allocation of energy throughout the anchovy lifecycle. For a 5-year simulation, we calculated the mean population growth rate $\left(r_{\mathrm{p}}\right)$ to be 3.4 year $^{-1}$. The primary parameters $\left[\dot{p}_{\mathrm{M}}\right]$, $\left[E_{\mathrm{G}}\right]$, and $\left[E_{\mathrm{M}}\right]$ were estimated at $48 \mathrm{~J} \mathrm{~cm}^{-3}$ day $^{-1}, 4,000 \mathrm{~J}$ $\mathrm{cm}^{-3}$, and $2,700 \mathrm{~J} \mathrm{~cm}^{-3}$, respectively. The population-level simulation was initialised with one cohort, consisting of one yolk-sac larva. The stage durations of individual traits are dependent on two forcing variables: SST and food density. The present study serves as a basis for further 
analyses of anchovy population health in the northwest Pacific Ocean.

\section{ACKNOWLEDGEMENTS}

This study was funded by the National Key R\&D Program of China (Grant no. 2017YFE0104400), National Basic Research Program of China (grant number 2015CB453303), the Joint Funds of the National Natural Science Foundation of China (grant number U1806202), AoShan Talents Cultivation Program Supported by Qingdao National Laboratory for MarinemScience and Technology (2017ASTCP-ES07) and the Research Program Supported by Laboratory for Marine Fisheries Science and Food Production Processes, Qingdao National Laboratory for Marine Science and Technology, China (grant number 2016LMFS-B14). The authors thank Dr Yan Jiao, Dr Kui Zhang, Dr Yongjiu Feng and Dr Lisha Guan for sharing their expertise on the research. Specifically, we thank the Dr Jacob Johansen, Steve O'Shea and Andrew Bullen for their assistance on earlier drafts of the manuscript, and the two anonymous reviewers for their many helpful comments.

\section{Statement of conflict of interest}

The authors have declared no conflict of interest.

\section{REFERENCES}

Agüera, A., Ahn, I.Y., Guillaumot, C., Bruno, D. and De-Hua, W., 2017. A Dynamic Energy Budget (DEB) model to describe Laternula elliptica (King, 1832) seasonal feeding and metabolism. PLoS One, 12: e0183848. https://doi.org/10.1371/journal. pone. 0183848

Birnir, B., Carpio, A., Cebrián, E. and Vidal, P., 2018. Dynamic energy budget approach to evaluate antibiotic effects on biofilms. Commun. Nonlin. Sci. Num. Simul., 54: 70-83. https://doi.org/10.1016/j. cnsns.2017.05.016

Bolker, B.M., 2008. Ecological models and data in R. Princeton University Press, pp.114-216. https://doi. org/10.1515/9781400840908

Boussouar, A., Le Bihan, S., Arino, O. and Prouzet, P., 2001. Mathematical model and numerical simulations of the migration and growth of Biscay Bay anchovy early larval stages. Oceanol. Acta, 24: 489-504. https://doi.org/10.1016/S03991784(01)01167-7

Celisse, A., 2008. Model selection via cross-validation in density estimation, regression, and changepoints detection. Doctoral dissertation, Université
Paris Sud-Paris XI.

Chen, C.S., Tzeng, C.H. and Chiu, T.S., 2010. Morphological and molecular analyses reveal separations among spatiotemporal populations of anchovy (Engraulis japonicus) in the southern East China Sea. Zool. Stud., 49: 270-282.

Chiu, T.S. and Chen, C.S., 2001. Growth and temporal variation of two Japanese anchovy cohorts during their recruitment to the East China Sea. Fish. Res., 53: 1-15. https://doi.org/10.1016/S01657836(00)00294-0

Desforges, J.P.W., Sonne, C. and Dietz, R., 2017. Using energy budgets to combine ecology and toxicology in a mammalian sentinel species. Scient. Rep., 7: srep46267. https://doi.org/10.1038/srep46267

Ellner, S.P. and Rees, M., 2006. Integral projection models for species with complex demography. Am. Natural., 167: 410-428. https://doi. org/10.1086/499438

Gelman, A., Hwang, J. and Vehtari, A., 2014. Understanding predictive information criteria for Bayesian models. Stat. Comput., 24: 997-1016. https://doi.org/10.1007/s11222-013-9416-2

Grossowicz, M., Marques, G.M. and Voorn, G.A.K.V., 2017. A dynamic energy budget (deb) model to describe population dynamics of the marine cyanobacterium prochlorococcus marinus. Ecol. Model., 359: 320-332. https://doi.org/10.1016/j. ecolmodel.2017.06.011

Hao, W., Jian, S., Ruijing, W., Lei, W. and Yi'an, L., 2003. Tidal front and the convergence of anchovy (Engraulis japonicus) eggs in the yellow sea fish. Oceanography, 12: 434-442. https://doi. org/10.1046/j.1365-2419.2003.00259.x

Iseki, K. and Kiyomoto, Y., 1997. Distribution and settling of Japanese anchovy (Engraulis japonicus) eggs at the spawning ground off Changjiang River in the East China Sea. Fish. Oceanogr., 6: 205-210. https://doi.org/10.1046/j.1365-2419.1997.00040.x

Iversen, S.A., Zhu, D., Johannessen, A. and Toresen, R., 1993. Stock size, distribution and biology of anchovy in the Yellow Sea and East China Sea. Fish. Res., 16: 147-163. https://doi.org/10.1016/01657836(93)90049-D

Jager, T. and Klok, C., 2010. Extrapolating toxic effects on individuals to the population level: the role of dynamic energy budgets. Philos. Trans. R. Soc. London B: Biol. Sci., 365: 3531-3540. https://doi. org/10.1098/rstb.2010.0137

Jin, X., 2004. Long-term changes in fish community structure in the Bohai Sea, China. Estuar. Coast. Shelf. Sci., 59: 163-171. https://doi.org/10.1016/j. 
ecss.2003.08.005

Jiang, Y.Y. and Zhuang, Z.M., 2005. Mitochondrial DNA sequence variation of Japanese anchovy Engraulis japonicus from the Yellow Sea and East China Sea. Fish. Sci., 71: 299-307. https://doi.org/10.1111/ j.1444-2906.2005.00964.x

Jin, X.S., Johannes, H., Zhao, X.Y. and Li, F.G., 2001. Study on the quota management of anchovy (Engraulis japonicus) in the Yellow Sea. J. Fish. Sci. China, 8: 27-30.

Jin, X. and Tang, Q., 1996. Changes in fish species diversity and dominant species composition in the Yellow Sea. Fish. Res., 26: 337-352. https://doi. org/10.1016/0165-7836(95)00422-X

Jusup, M., Klanjscek, T., Matsuda, H. and Kooijman, S.A.L.M., 2011. A full lifecycle bioenergetic model for bluefin tuna. PLoS One, 6: e21903. https://doi. org/10.1371/journal.pone.0021903

Kim, J.Y., Kang, Y.S., Oh, H.J., Suh, Y.S. and Hwang, J.D., 2005. Spatial distribution of early life stages of anchovy (Engraulis japonicus) and hairtail (Trichiurus lepturus) and their relationship with oceanographic features of the East China Sea during the 1997-1998 El Niño Event. Estuar., Coast. Shelf. Sci., 63: 13-21. https://doi.org/10.1016/j. ecss.2004.10.002

Kooijman, S.A.L.M., 2010. Dynamic energy budgets theory for metabolic organization, 3rd edition. Cambridge University Press, Great Britain.

Lin, L., Zhu, L., Liu, S.F., Su, Y.Q. and Zhuang, Z.M., 2011. Polymorphic microsatellite loci for the Japanese anchovy Engraulis japonicus (Engraulidae). Genet. mol. Res., 10: 764-768. https://doi.org/10.4238/ vol10-2gmr1085

Lika, K., Kearney, M.R., Freitas, V., van der Veer, H.W., van der Meer, J., Wijsman, J.W. and Kooijman, S.A., 2011. The covariation method for estimating the parameters of the standard dynamic energy budget model I: Philosophy and approach. $J$. Sea Res., 66: 270-277. https://doi.org/10.1016/j. seares.2011.07.010

van der Meer, J., 2006. An introduction to Dynamic Energy Budget (DEB) models with special emphasis on parameter estimation. J. Sea Res., 56: 85-102. https://doi.org/10.1016/j.seares.2006.03.001

Maley, C.C. and Caswell, H., 1993. Implementing I-state configuration models for population dynamics: An object-oriented programming approach. Ecol. Model., 68: 75-89. https://doi.org/10.1016/03043800(93)90109-6

Marn, N., 2016. Life cycle and ecology of the loggerhead turtle (Caretta caretta, Linnaeus, 1758). development and application of the Dynamic Energy Budget model. Ph.D. thesis. Amsterdam University. Martin, B.T., Jager, T., Nisbet, R.M., Preuss, T.G., Hammers-Wirtz, M. and Grimm, V., 2013. Extrapolating ecotoxicological effects from individuals to populations: a generic approach based on Dynamic Energy Budget theory and individualbased modeling. Ecotoxicology, 22: 574-583. https:// doi.org/10.1007/s10646-013-1049-x

Meng, T., 2002. Studies on the feeding of anchovy (Engraulis japonicus) at different life stages on zooplankton in the middle and southern waters of the Yellow Sea. Mar. Fish. Res., 24: 1-9.

Nisbet, E.K., Zelenski, J.M. and Murphy, S.A., 2012. Happiness is in our nature: Exploring nature relatedness as a contributor to subjective well-being. J. Happin. Stud., 13: 303-322.

Ohshimo, S., 1996. Acoustic estimation of biomass and school character of anchovy Engraulis japonicus in the East China Sea and the Yellow Sea. Fish. Sci., 62: 344-349. https://doi.org/10.2331/fishsci.62.344

Pethybridge, H., Roos, D., Loizeau, V., Pecquerie, L. and Bacher, C., 2013. Responses of European anchovy vital rates and population growth to environmental fluctuations: an individual-based modeling approach. Ecol. Model., 250: 370-383. https://doi. org/10.1016/j.ecolmodel.2012.11.017

Pecquerie, L., Petitgas, P. and Kooijman, S.A., 2009. Modeling fish growth and reproduction in the context of the dynamic energy budget theory to predict environmental impact on anchovy spawning duration. J. Sea Res., 62: 93-105. https://doi. org/10.1016/j.seares.2009.06.002

Railsback, S.F. and Grimm, V., 2011. Agent-based and individual-based modeling: A practical introduction. Princeton University Press.

Regner, S., 1996. Effects of environmental changes on early stages and reproduction of anchovy in the Adriatic Sea. Sci. Mar., 60: 167-177.

Serpa, D., Ferreira, P.P., Ferreira, H., da Fonseca, L.C., Dinis, M.T. and Duarte, P., 2013. Modelling the growth of white seabream (Diplodus sargus) and gilthead seabream (Sparus aurata) in semi-intensive earth production ponds using the Dynamic Energy Budget approach. J. Sea Res., 76: 135-145. https:// doi.org/10.1016/j.seares.2012.08.003

Shan, X., Li, X., Yang, T., Sharifuzzaman, S.M., Zhang, G., Jin, X. and Dai, F., 2017. Biological responses of small yellow croaker (Larimichthys polyactis) to multiple stressors: A case study in the Yellow Sea, China. Acta Oceanolog. Sin., 36: 39-47. https://doi. org/10.1007/s13131-017-1091-2 
Sibly, R.M., Grimm, V., Martin, B.T., Johnston, A.S., Kułakowska, K., Topping, C.J. and DeAngelis, D.L., 2013. Representing the acquisition and use of energy by individuals in agent-based models of animal populations. Methods Ecol. Evolut., 4: 151161. https://doi.org/10.1111/2041-210x.12002

Smallegange, I.M., Caswell, H., Toorians, M.E. and Roos, A.M., 2017. Mechanistic description of population dynamics using dynamic energy budget theory incorporated into integral projection models. Meth. Ecol. Evol., 8: 146-154.

Sun, Y., Ma, Z.M., Liu, Y. and Tang Q.S., 2006. The gastric evacuation rate of anchovy (Engraulis japonicus) in different growth stages in Huanghai Sea and East China Sea (in Chinese with English abstract). Acta Oceanolog. Sin., 28: 103-108.

Temminck, C.J. and Schlegel, H., 1846. Pisces, parts 5-6. In: Fauna Japonica, sive descriptio animalium quae in itinere per Japoniam suscepto annis 1823-30 collegit, notis observationibus et adumbrationibus illustravit (ed. P.F. de Siebold). Ludguni Batavorum, Leiden, pp 73-112.

Wan, R., Huang, D. and Zhang, J., 2002. Abundance and distribution of eggs and larvae of engraulis japonicus in the northern part of East China Sea and the southern part of Yellow Sea and its relationship with environmental conditions. Shuichan Xuebao, 26: 321-330.

Wan, R.J., Li, X.S., Zhuang, Z.M. and Meng, Z.N., 2004. Experimental starvation on Engraulis japonicus larvae and definition of the point of no return. $J$. Fish. China, 28: 79-84.

Wan, R. and Bian, X., 2012. Size variability and natural mortality dynamics of anchovy Engraulis japonicus eggs under high fishing pressure. Mar. Ecol. Progr. Ser., 465: 243-251. https://doi.org/10.3354/ meps09795

Wang, R., Chen, Y.Q., Zuo, T. and Wang, K., 2003. Quantitative distribution of euphausiids in the
Yellow Sea and East China Sea in spring and autumn in relation to the hydrographic conditions. J. Fish. China, 27: 31-38.

Zhao, X.Y., 2006. Population dynamic characteristics and sustainable utilization of the anchovy stock in the Yellow Sea. Doctor Dissertation. Ocean University of China, Qingdao (In Chinese with English abstract).

Zhao, X., Wang, Y. and Dai, F., 2008. Depth-dependent target strength of anchovy (Engraulis japonicus) measured in situ. ICES J. Mar. Sci., 65: 882-888. https://doi.org/10.1093/icesjms/fsn055

Zhao, X., Hamre, J., Li, F., Jin, X. and Tang, Q., 2003. Recruitment, sustainable yield and possible ecological consequences of the sharp decline of the anchovy (Engraulis japonicus) stock in the Yellow Sea in the 1990s. Fish. Oceanogr., 12: 495-501. https://doi.org/10.1046/j.1365-2419.2003.00262.x

Zhinan, Z., Fanghong, M., Zhishan, Y. and Jie, H., 2002. Abundance and biomass of the benthic meiofauna in the spawning ground of anchovy (Engraulis japanicus) in the Southern Yellow Sea, China. J. Ocean Univ. Qingdao, 32: 251-258.

Zhu, D., 1990. Anchovy and other fish resources in the Yellow Sea and East China Sea. Mar. Fish. Res. China, 11: 1-143.

Zhu, D.S. and Iversen, S.A., 1990. Anchovy and other fish resources in the Yellow Sea and East China Sea. Mar. Fish. Res., 11: 1-143 (in Chinese with English abstract).

Zhu, J.C., Zhao, X.Y. and Li, F.G., 2007. Growth characters of the anchovy stock in the Yellow Sea with its annual and seasonal variations. Mar. Fish. Res., 28: 64-72.

Zuidema, P.A., Jongejans, E., Chien, P.D., During, H.J. and Schieving, F., 2010. Integral projection models for trees: a new parameterization method and a validation of model output. J. Ecol., 98: 345-355. https://doi.org/10.1111/j.1365-2745.2009.01626.x 